Pacific Journal of Mathematics

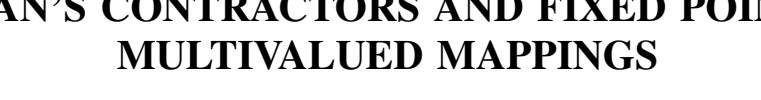




\title{
ALTMAN'S CONTRACTORS AND FIXED POINTS OF MULTIVALUED MAPPINGS
}

\author{
K. BALAKRIShNa Reddy and P. V. SUbRAhmanyam
}

Let $P_{i}: D \subset X_{1} \times \cdots \times X_{n} \rightarrow \mathrm{CL}\left(Y_{i}\right)$ be multivalued mappings where $X_{\imath}, Y_{i}$ are Banach spaces and $\mathrm{CL}\left(Y_{i}\right)$ is the set of all nonempty closed subsets of $Y_{i}, i=1, \cdots, n$. We prove a theorem ensuring that $\theta_{i} \in P_{i}\left(x_{1}, \cdots, x_{n}\right)$ for some $\left(x_{1}, \cdots, x_{n}\right) \in D$ and deduce the fixed point theorems for multivalued mappings proved earlier by Czerwik, Nadler and Reich as corollaries. Besides, generalizations for multivalued mappings of the existence theorems proved by Altman using his theory of contractors are also obtained.

1. Introduction. In [2] we showed how the fixed point theorems of Altman [1] and Matkowski ([5], [6]) can be unified in the set-up of Banach spaces. The present paper studies further the relationship between Altman's theory of contractors and Matkowski's fixed point theorem and offers an existence theorem for the multivalued operator equation $\theta \in P x$ on subsets of a Banach space. We deduce as a corollary a comprehensive fixed point theorem proved by Czerwik [4] for multivalued mappings. Czerwik's fixed point theorem generalized the earlier fixed point theorems for set valued transformations on metric spaces obtained by Nadler [7], Covitz and Nadler [3] and Reich [9]. Apart from Czerwik's theorem, our main result obtains as corollaries generalizations to multivalued mappings of Altman's existence theorems and Matkowski's fixed point theorem. Section 3 gives the main result of the paper, while $\S 2$ provides preliminaries basic to $\S 3$.

2. Let $X$ be a Banach space. We employ the following notation of [7] and [8]:

$$
\begin{aligned}
& \mathrm{CL}(X)=\{C: C \text { is a nonempty closed subset of } X\} \text {. } \\
& N(\varepsilon, C)=\{x \in X:\|x-c\|<\varepsilon \text { for some } c \in C\}, \\
& \varepsilon>0, C \in \mathrm{CL}(X) \text {. } \\
& H(A, B)= \begin{cases}\text { inf } \varepsilon>0, & A \subset N(\varepsilon, B) \text { and } B \subset N(\varepsilon, A), \\
& \text { if the infimum exists }, \\
\infty, & \text { otherwise },\end{cases} \\
& A, B \in \mathrm{CL}(X) \text {. }
\end{aligned}
$$

The function $H$ is called the generalized Hausdorff distance for 
CL $(X)$ induced by the norm of $X$.

$$
D(x, A)=\inf \{\|x-a\|: a \in A\} .
$$

The lemma given below is well-known and is used in $\S 3$.

Lemma 2.1. Suppose $A, B \in \mathrm{CL}(X)$ and $a \in A$. Then, for $q>0$, there exists an element $b \in B$ such that

$$
d(a, b) \leqq H(A, B)+q
$$

A point $x \in X$ is said to be a fixed point for the multivalued mapping $f: X \rightarrow \mathrm{CL}(X)$ if $x \in f(x)$.

We follow the notation of [6].

Let $\left(a_{i k}\right)$ be an $n \times n$ nonnegative matrix. Define

$$
\begin{gathered}
a_{i k}^{1}=\left\{\begin{array}{ll}
a_{i k}, & i \neq k, \\
1-a_{i k}, & i=k,
\end{array} \quad i, k=1, \cdots, n .\right. \\
a_{i k}^{l+1}= \begin{cases}a_{11}^{l} a_{i+1 k+1}^{l}+a_{i+11}^{l} a_{1 k+1}^{l}, & i \neq k \\
a_{11}^{l} a_{i+1 k+1}^{l}-a_{i+11}^{l} a_{1 k+1}^{l}, & i=k\end{cases} \\
\quad l=1, \cdots, n-1 ; \quad i, k=1, \cdots, n-l
\end{gathered}
$$

Matkowski ([5], [6]) proved the following

LEMmA 2.2. Let $a_{i k}^{1}>0, i, k=1, \cdots, n$. The system of inequalities

$$
\sum_{k=1}^{n} a_{i k} r_{k}<r_{i}, \quad i=1, \cdots, n,
$$

has a solution $r_{i}>0, i=1, \cdots, n$ if and only if the following inequalities hold:

$$
a_{i i}^{l}>0, \quad l=1, \cdots, n ; \quad i=1, \cdots, n+1-l .
$$

Using this lemma he obtained the following fixed point theorem. (Actually Matkowski proved this theorem in the setting of complete metric spaces.)

THEOREM 2.1. Let $X_{i}$ be Banach spaces and $T_{i}: X_{1} \times \cdots \times X_{n} \rightarrow$ $X_{i}, i=1, \cdots, n$ be mappings such that

$$
\begin{aligned}
\left\|T_{i}\left(x_{1}, \cdots, x_{n}\right)-T_{i}\left(y_{1}, \cdots, y_{n}\right)\right\| \leqq \sum_{k=1}^{n} a_{i k}\left\|x_{k}-y_{k}\right\|, \\
\quad i=1, \cdots, n, \quad x_{k}, y_{k} \in X_{k}, \quad k=1, \cdots, n,
\end{aligned}
$$

where $a_{i k}>0, i, k=1, \cdots, n$. If the numbers $a_{i k}^{l}, l=1, \cdots, n$; 
$i, k=1, \cdots, n+1-l$ defined by (2.5) and (2.6) fulfill (2.8), then the system of equations

$$
x_{i}=T_{i}\left(x_{1}, \cdots, x_{n}\right), \quad i=1, \cdots, n,
$$

has exacty one solution $x_{i} \in X_{i}, i=1, \cdots, n$. Moreover,

$$
x_{i}=\lim _{m \rightarrow \infty} x_{i}^{m}, \quad i=1, \cdots, n,
$$

where $x_{i}^{m+1}=T_{i}\left(x_{1}^{m}, \cdots, x_{n}^{m}\right), \stackrel{\circ}{x}_{i} \in X_{i}, i=1, \cdots, n$ is arbitrarily chosen.

Considerations of some of the fundamental problems of numerical analysis and operator theory led Altman [1] to the concept of contractors.

Definition 2.1 [p. 8, [1]]. Let $P: D(P) \subset X \rightarrow Y, D(P)$ being the domain of $P$, be a nonlinear operator from a Banach space $X$ to a Banach space $Y$ and $\Gamma(x): Y \rightarrow X$ be a bounded linear operator associated with $x \in X$. We say that $P$ has a contractor $\Gamma(x)$ if there is a positive number $q<1$ such that

$$
\|P(x+\Gamma(x) y)-P x-y\| \leqq q\|y\|,
$$

where $x \in D(P), y \in Y$ are defined by the particular problem.

Definition 2.2 [p. 10, [1]]. A contractor $\Gamma(x)$ is called regular if (2.10) is satisfied for all $y \in Y$ and $D(P)=\Gamma(x)(Y)$.

Definition 2.3 [p. 6, [1]]. An operator $P: D(P) \subset X \rightarrow Y$ is closed on $D(P)$ if $x_{n} \in D(P), x_{n} \rightarrow x$ and $P x_{n} \rightarrow y$ imply $x \in D(P)$ and $P x=y$.

Altman proved the following theorem:

THEOREM 2.2 [p. 13, Theorem 5.1, [1]]. Suppose that the closed nonlinear operator $P: D(P) \subset X \rightarrow Y$ has a bounded contractor $\Gamma$ such that

(a) $\quad x+\Gamma(x) y \in D(P)$, whenever $x \in D(P), \quad y \in Y$;

(b) $\quad\|P(x+\Gamma(x) y)-P x-y\| \leqq q\|y\|, y \in Y, 0<q<1$;

$$
\|\Gamma(x)\| \leqq B \text { for all } x \in D(P) .
$$

Then the equation $P x=y$ has a solution for $y \in Y$. When $\Gamma$ is regular, the assumption (2.11)(a) is readily satisfied and further, the solution is unique. 
3. We generalize the notion of a closed operator to multivalued mappings as follows:

Definition 3.1. A nonlinear multivalued operator $P: D(P) \subset$ $X \rightarrow \mathrm{CL}(Y), X, Y$ being Banach spaces, is closed on $D(P)$, if $x_{n} \rightarrow x$, $y_{n} \in P x_{n}$ and $y_{n} \rightarrow y$ imply that $x \in D(P)$ and $y \in P x$.

Let $X_{i}, Y_{i}, i=1, \cdots, n$ be Banach spaces and $b_{\imath k}, c_{i k} \geqq 0 i, k=$ $1, \cdots, n$. Let $a_{\imath k}=b_{\imath k}+c_{\imath k}, i, k=1, \cdots, n$, be positive and the numbers $a_{i k}^{l}$ defined by (2.5) and (2.6) fulfill (2.8). Then, by Lemma 2.2 , there exists a positive solution $r_{1}, \cdots, r_{n}$ of the system of inequalities (2.7). We define

$$
q=\max _{i}\left(r_{i}^{-1} \sum_{k=1}^{n} a_{i k} r_{k}\right) .
$$

Clearly, $0<q<1$, and

$$
\sum_{k=1}^{n} a_{i k} r_{k} \leqq q r_{i}, \quad i=1, \cdots, n .
$$

THEOREM 3.1. Suppose that the closed nonlinear transformations $P_{i}: D \subset X_{1} \times \cdots \times X_{n} \rightarrow \mathrm{CL}\left(Y_{\imath}\right), i=1, \cdots, n$ fulfill the following:

there exist bounded linear operators $\Gamma_{i}\left(x_{i}\right): Y_{\imath} \rightarrow X_{i}, x_{\imath} \in X_{\imath}$, (3.3) $\quad i=1, \cdots, n$ such that

$$
\left\|\Gamma_{i}\left(x_{i}\right)\right\| \leqq B, \quad\left(x_{1}, \cdots, x_{n}\right) \in D, \quad i=1, \cdots, n ;
$$

(3.4) (a) $\quad\left(x_{1}+\Gamma_{1}\left(x_{1}\right) y_{1}, \cdots, x_{n}+\Gamma_{n}\left(x_{n}\right) y_{n}\right) \in D$ whenever

$$
\left(x_{1}, \cdots, x_{n}\right) \in D \text { and } y_{i} \in Y_{i}, \quad i=1, \cdots, n \text {; }
$$

(b) $\quad H_{i}\left[P_{i}\left(x_{1}+\Gamma_{1}\left(x_{1}\right) y_{1}, \cdots, x_{n}+\Gamma_{n}\left(x_{n}\right) y_{n}\right), P_{i}\left(x_{1}, \cdots, x_{n}\right)+y_{i}\right]$

$$
\begin{aligned}
& \leqq \sum_{k=1}^{n} b_{\imath k}\left\|y_{k}\right\|+\sum_{k=1}^{n} c_{i k} D_{k}\left[y_{k}, y_{k}-P_{k}\left(x_{1}, \cdots, x_{n}\right)\right] \\
& \quad+c D_{i}\left[y_{\imath}, y_{i}\right. \\
& \left.\quad-\Gamma_{\imath}\left(x_{i}\right) P_{\imath}\left(x_{1}+\Gamma_{1}\left(x_{1}\right) y_{1}, \cdots, x_{n}+\Gamma_{n}\left(x_{n}\right) y_{n}\right)\right] \\
& \quad \text { for } \quad\left(x_{1}, \cdots, x_{n}\right) \in D, \quad y_{\imath} \in Y_{i}, \quad i=1, \cdots, n,
\end{aligned}
$$

where $a_{\imath k}=b_{i k}+c_{i k}, i, k=1, \cdots, n$ are positive and the numbers $a_{i k}^{l}$ defined by (2.5) and (2.6) satisfy (2.8);

$$
c \text { is a constant such that } 0 \leqq c B<1-q \text {. }
$$

Then there exists $\left(x_{1}, \cdots, x_{n}\right) \in D$ such that $\theta_{i} \in P_{i}\left(x_{1}, \cdots, x_{n}\right) \quad i=$ $1, \cdots, n$, where $\theta_{i}$ is the zero element of the Banach space $Y_{i}$, $i=1, \cdots, n$.

Proof. Let $\left(\grave{x}_{1}, \cdots, \grave{x}_{n}\right) \in D$ be an arbitrary element. Choose 
$\grave{y}_{i} \in P_{i}\left(\grave{x}_{1}, \cdots, \grave{x}_{n}\right), i=1, \cdots, n$. We can assume without loss of generality that $\|\grave{y}\| \leqq r_{i}, r_{i} \geqq 1, i=1, \cdots, n$, since the set of solutions to the system (2.7) is closed with respect to multiplication by positive scalars. Define

$$
x_{i}^{1}=\dot{x}_{i}-\Gamma_{i}\left(\dot{x}_{i}\right) \dot{y}_{i}, \quad i=1, \cdots, n .
$$

Replacing $x_{i}$ by $\dot{x}_{i}$ and $y_{i}$ by $-\dot{y}_{i}$ in (3.4)(b) and using (3.6) we get,

$$
\begin{aligned}
& H_{i}\left[P_{i}\left(x_{1}^{1}, \cdots, x_{n}^{1}\right), P_{i}\left(\stackrel{\circ}{x}_{1}, \cdots, \dot{x}_{n}\right)-\grave{y}_{i}\right] \\
& \leqq \sum_{k=1}^{n} b_{i k}\left\|\dot{y}_{k}\right\|+\sum_{k=1}^{n} c_{i k} D_{k}\left[-\grave{y}_{k},-\dot{y}_{k}-P_{k}\left(\dot{x}_{1}, \cdots, \dot{x}_{n}\right)\right] \\
& +c D_{i}\left[-\stackrel{\circ}{y}_{i},-\dot{\circ}_{i}-\Gamma_{i}\left(\dot{x}_{i}\right) P_{i}\left(x_{1}^{1}, \cdots, x_{n}^{1}\right)\right] \\
& \leqq \sum_{k=1}^{n} b_{i k}\left\|\stackrel{\circ}{y}_{k}\right\|+\sum_{k=1}^{n} c_{i k}\left\|\dot{\circ}_{k}\right\|+c D_{i}\left[\theta_{i}, \Gamma_{i}\left(\dot{x}_{i}\right) P_{i}\left(x_{1}^{1}, \cdots, x_{n}^{1}\right)\right] \text {. }
\end{aligned}
$$

As $\dot{y}_{i} \in P_{i}\left(\dot{x}_{1}, \cdots, \dot{x}_{n}\right), \quad \theta_{i} \in P_{i}\left(\dot{x}_{1}, \cdots, \dot{x}_{n}\right)-\dot{y}_{i}, i=1, \cdots, n$. So, for $q>0$, by Lemma 2.1 , there exists an element $y_{i}^{1} \in P_{i}\left(x_{1}^{1}, \cdots, x_{n}^{1}\right), i=$ $1, \cdots, n$ such that

$$
\left\|y_{i}^{1}-\theta_{i}\right\| \leqq H_{i}\left[P_{i}\left(x_{1}^{1}, \cdots, x_{n}^{1}\right), P_{i}\left(\dot{x}_{1}, \cdots, \grave{x}_{n}\right)-\grave{y}_{i}\right]+q .
$$

From (3.7) and (3.8) we have

$$
\begin{aligned}
& \left\|y_{i}^{1}\right\| \leqq \sum_{k=1}^{n}\left(b_{i k}+c_{i k}\right)\left\|\stackrel{\circ}{y}_{k}\right\|+c\left\|\Gamma_{i}\left(x_{i}\right) y_{i}^{1}\right\|+q \\
& \leqq \sum_{k=1}^{n} a_{i k}\left\|\stackrel{\circ}{k}_{k}\right\|+c B\left\|y_{i}^{1}\right\|+q \text {, by (3.3) }
\end{aligned}
$$

$$
\begin{aligned}
(1-c B)\left\|y_{i}^{1}\right\| & \leqq \sum_{k=1}^{n} a_{i k} r_{k}+q, \text { by our assumption } \\
& \leqq q r_{i}+q, \text { by }(3.2) \\
& \leqq 2 q r_{i}, \text { as } r_{i} \geqq 1, \quad i=1, \cdots, n \text { and } 0<q<1 .
\end{aligned}
$$

Hence

$$
\left\|y_{i}^{1}\right\| \leqq \frac{2 q}{(1-c B)} r_{i}, \quad i=1, \cdots, n
$$

We shall now construct inductively sequences $\left\{x_{i}^{m}\right\}$ and $\left\{y_{i}^{m}\right\} i=1, \cdots, n$ such that

$$
\begin{aligned}
& \text { (a) } \quad\left(x_{1}^{m}, \cdots, x_{n}^{m}\right) \in D, \quad y_{i}^{m} \in P_{i}\left(x_{1}^{m}, \cdots, x_{n}^{m}\right) \\
& \text { (b) } \quad\left\|y_{i}^{m}\right\| \leqq(m+1)\left(\frac{q}{1-c B}\right)^{m} r_{i}, \quad i=1, \cdots, n .
\end{aligned}
$$

For $m=1$, the above hypotheses are true, in view of (3.4)(a), (3.6) and (3.9). Assume the truth of $(3.10)(a),(3.10)(b)$ for $m-1 \in N$, i.e., 
$(3.11)$

(a) $\quad\left(x_{1}^{m-1}, \cdots, x_{n}^{m-1}\right) \in D, \quad y_{\imath}^{m-1} \in P_{i}\left(x_{1}^{m-1}, \cdots, x_{n}^{m-1}\right)$,

(b) $\quad\left\|y_{i}^{m-1}\right\| \leqq m\left(\frac{q}{1-c B}\right)^{m-1} r_{i}, \quad i=1, \cdots, n$.

Define

$$
x_{i}^{m}=x_{i}^{m-1}-\Gamma_{i}\left(x_{i}^{m}\right) y_{i}^{m-1}, \quad i=1, \cdots, n .
$$

In (3.4)(b), replacing $x_{i}$ by $x_{i}^{m-1}, y_{i}$ by $-y_{i}^{m-1}$ and using (3.12) we have

$$
\begin{aligned}
& H_{i}\left[P_{i}\left(x_{1}^{m}, \cdots, x_{n}^{m}\right), P_{i}\left(x_{1}^{m-1}, \cdots, x_{n}^{m-1}\right)-y_{i}^{m-1}\right] \\
& \leqq \\
& \quad \sum_{k=1}^{n} b_{i k}\left\|y_{k}^{m-1}\right\|+\sum_{k=1}^{n} c_{i k} D_{k}\left[-y_{k}^{m-1},-y_{k}^{m-1}-P_{k}\left(x_{1}^{m-1}, \cdots, x_{n}^{m-1}\right)\right] \\
& \quad+c D_{i}\left[-y_{i}^{m-1},-y_{i}^{m-1}-\Gamma_{i}\left(x_{i}^{m-1}\right) P_{i}\left(x_{1}^{m}, \cdots, x_{n}^{m}\right)\right] \\
& \leqq \\
& \quad \sum_{k=1}^{n} b_{i k}\left\|y_{k}^{m-1}\right\|+\sum_{k=1}^{n} c_{i k}\left\|y_{k}^{m-1}\right\| \\
& \quad+c D_{i}\left[\theta_{i}, \Gamma_{i}\left(x_{i}^{m-1}\right) P_{i}\left(x_{1}^{m}, \cdots, x_{n}^{m}\right)\right] .
\end{aligned}
$$

Since $\theta_{i} \in P_{i}\left(x_{1}^{m-1}, \cdots, x_{n}^{m-1}\right)-y_{i}^{m-1}$, given $q /(1-c B)^{m-1}>0$, there exists $y_{i}^{m} \in P_{i}\left(x_{1}^{m}, \cdots, x_{n}^{m}\right)$ such that

$$
\begin{aligned}
& \left\|y_{i}^{m}-\theta_{i}\right\| \leqq H_{i}\left[P_{i}\left(x_{1}^{m}, \cdots, x_{n}^{m}\right), P_{i}\left(x_{1}^{m-1}, \cdots, x_{n}^{m-1}\right)-y_{i}^{m-1}\right] \\
& +\frac{q^{m}}{(1-c B)^{m-1}} \text {. }
\end{aligned}
$$

From (3.13) and (3.14) we get

$$
\begin{aligned}
\left\|y_{i}^{m}\right\| \leqq \sum_{k=1}^{n}\left(b_{i k}+c_{i k}\right)\left\|y_{k}^{m-1}\right\|+c B\left\|y_{i}^{m}\right\|+\frac{q^{m}}{(1-c B)^{m-1}} \\
(1-c B)\left\|y_{\imath}^{m}\right\| \leqq m\left(\frac{q}{1-c B}\right)^{m-1} \sum_{k=1}^{n} a_{i k} r_{k}+\frac{q^{m}}{(1-c B)^{m-1}} \\
\leqq \operatorname{mar}_{i}\left(\frac{q}{1-c B}\right)^{m-1}+\frac{q^{m}}{(1-c B)^{m-1}}, \quad \text { by }
\end{aligned}
$$

i.e.,

$$
\begin{aligned}
\left\|y_{i}^{m}\right\| & \leqq m\left(\frac{q}{1-c B}\right)^{m} r_{i}+\left(\frac{q}{1-c B}\right)^{m} r_{i} \\
& \leqq(m+1)\left(\frac{q}{1-c B}\right)^{m} r_{i}, \text { as } r_{i} \geqq 1, \quad i=1, \cdots, n .
\end{aligned}
$$

Hence by induction $(3.10)(b)$ holds for all $m=0,1,2, \cdots$. From (3.12), and (3.4)(a), it follows that $\left(x_{1}^{m}, \cdots, x_{n}^{m}\right) \in D$. By construction, $y_{\imath}^{m} \in P_{i}\left(x_{1}^{m}, \cdots, x_{n}^{m}\right)$. Hence by induction (3.10)(a) holds. By (3.5), $0 \leqq q /(1-c B)<1$ and it follows from (3.10)(b) that $y_{i}^{m} \rightarrow \theta_{i}$, as $m \rightarrow \infty, i=1, \cdots, n$. From (3.12), 


$$
\begin{aligned}
\left\|x_{i}^{m+1}-x_{i}^{m}\right\| & \leqq\left\|\Gamma_{i}\left(x_{i}^{m}\right) y_{i}^{m}\right\| \\
& \leqq B(m+1)\left(\frac{q}{1-c B}\right)^{m} r_{i} .
\end{aligned}
$$

Hence $\left\{x_{i}^{m}\right\}$ is a Cauchy sequence in $X_{i}, i=1, \cdots, n$. Therefore, $x_{i}^{m} \rightarrow x_{i}, i=1, \cdots, n$. As the operator $P_{i}$ is closed, $y_{i}^{m} \in P_{i}\left(x_{1}^{m}, \cdots, x_{n}^{m}\right)$, $y_{i}^{m} \rightarrow \theta_{i}, \quad x_{i}^{m} \rightarrow x_{i}, \quad i=1, \cdots, n$, imply that $\left(\theta_{1}, \cdots, \theta_{n}\right) \in D$ and $\theta_{i} \in$ $P\left(x_{1}, \cdots, x_{n}\right), i=1, \cdots, n$.

We now deduce Czerwik's Theorem [4] as a corollary in the setup of Banach spaces. Czerwik proved his theorem for multivalued mappings on complete metric spaces.

THEOREM 3.2 [Theorem, [4]]. Let $X_{i}, i=1, \cdots, n$ be Banach spaces and $b_{i k}, c_{i k} \geqq 0$ for $i, k=1, \cdots, n$. Let $a_{i k}=b_{i k}+c_{i k}, i, k=$ $1, \cdots, n$ be positive and let the numbers $a_{i k}^{l}$ defined by (2.5) and (2.6) fulfill (2.8). Suppose that the transformations $F_{i}: X_{1} \times \cdots \times X_{n} \rightarrow$ CL $\left(X_{i}\right), i=1, \cdots, n$ fulfill

$$
\begin{aligned}
& H_{i}\left[F_{i}\left(x_{1}, \cdots, x_{n}\right), F_{i}\left(z_{1}, \cdots, z_{n}\right)\right] \\
& \leqq \\
& \quad \sum_{k=1}^{n} b_{i k}\left\|x_{k}-z_{k}\right\|+\sum_{k=1}^{n} c_{i k} D_{k}\left[x_{k}, F_{k}\left(x_{1}, \cdots, x_{n}\right)\right] \\
& \quad+c D_{i}\left[z_{i}, F_{i}\left(z_{1}, \cdots, z_{n}\right)\right], \quad i=1, \cdots, n ;
\end{aligned}
$$

for $x_{j}, z_{j} \in X_{j}, j=1, \cdots, n$, where $c$ fulfills the condition $0 \leqq c<$ $1-q, q$ being defined by

$$
q=\max _{i}\left(r_{i}^{-1} \sum_{k=1}^{n} a_{i k} r_{k}\right) .
$$

Then the system $\left(F_{1}, \cdots, F_{n}\right)$ has a fixed point, i.e., there exist points $x_{i} \in X_{i}, i=1, \cdots, n$ such that $x_{i} \in F_{i}\left(x_{1}, \cdots, x_{n}\right), i=1, \cdots, n$.

Proof. That the above theorem follows as a corollary for the Theorem 3.1 can be seen if we put $\Gamma_{i}\left(x_{i}\right)=I,\left(x_{i} \in X_{i}\right)$, the identity operator on $X_{i}$ and $P_{i}\left(x_{1}, \cdots, x_{n}\right)=x_{i}-F_{i}\left(x_{1}, \cdots, x_{n}\right) i=1, \cdots, n$ in (3.4)(b) and observe that it reduces to

$$
\begin{aligned}
& H_{i}\left[x_{i}+y_{i}-F_{i}\left(x_{1}+y_{1}, \cdots, x_{n}+y_{n}\right), x_{i}+y_{i}-F_{i}\left(x_{1}, \cdots, x_{n}\right)\right] \\
& \quad \leqq \sum_{k=1}^{n} b_{i k}\left\|y_{k}\right\|+\sum_{k=1}^{n} c_{i k} D_{k}\left[y_{k}, y_{k}-x_{k}+F_{k}\left(x_{1}, \cdots, x_{n}\right)\right] \\
& \quad+c D_{i}\left[x_{i}+y_{i}, x_{i}+y_{i}-\left(x_{i}+y_{i}\right)+F_{i}\left(x_{1}+y_{1}, \cdots, x_{n}+y_{n}\right)\right]
\end{aligned}
$$

i.e.,

$$
\begin{aligned}
& H_{i}\left[F_{i}\left(x_{1}+y_{1}, \cdots, x_{n}+y_{n}\right), F_{i}\left(x_{1}, \cdots, x_{n}\right)\right] \\
& \leqq \\
& \quad \sum_{k=1}^{n} b_{i k}\left\|y_{k}\right\|+\sum_{k=1}^{n} c_{i k}\left[y_{k}, y_{k}-x_{k}+F_{k}\left(x_{1}, \cdots, x_{n}\right)\right] \\
& \quad+c D_{i}\left[x_{i}+y_{i}, F_{i}\left(x_{1}+y_{1}, \cdots, x_{n}+y_{n}\right)\right] .
\end{aligned}
$$


Taking $x_{\imath}+y_{\imath}=z_{i}, i=1, \cdots, n$, we have

$$
\begin{aligned}
& H_{i}\left[F_{\imath}\left(x_{1}, \cdots, x_{n}\right), F_{i}\left(z_{1}, \cdots, z_{n}\right)\right] \\
& \leqq \sum_{k=1}^{n} b_{i k}\left\|x_{k}-z_{k}\right\|+\sum_{k=1}^{n} c_{i k} D_{k}\left[x_{k}, F_{k}\left(x_{1}, \cdots, x_{n}\right)\right] \\
& \quad+c D_{i}\left[z_{i}, F_{i}\left(z_{1}, \cdots, z_{n}\right)\right],
\end{aligned}
$$

which is nothing but condition (3.15). It can be similarly shown that (3.15) implies $(3.4)(\mathrm{b})$ in this case. To prove that the operator $F_{i}$, $i=1, \cdots, n$ is closed in the sense of Definition 3.1, observe that we have shown in the proof of Theorem 3.1 that $x_{i}^{m} \rightarrow x_{i}$ and $y_{i}^{m} \in$ $P_{i}\left(x_{1}^{m}, \cdots, x_{n}^{m}\right)$, i.e., $y_{\imath}^{m} \in x_{2}^{m}-F_{\imath}\left(x_{1}^{m}, \cdots, x_{n}^{m}\right) i=1, \cdots, n$, and $y_{i}^{m} \rightarrow 0$ as $m \rightarrow \infty$, i.e., $x_{i}^{m}-y_{i}^{m} \rightarrow x_{i}, i=1, \cdots, n$. It remains to show that $x_{i} \in F_{i}\left(x_{1}, \cdots, x_{n}\right), i=1, \cdots, n$.

$$
\begin{aligned}
& D_{i}\left[x_{i}, F_{i}\left(x_{1}, \cdots, x_{n}\right)\right] \\
& \leqq \\
& \leqq \\
& \leqq
\end{aligned}
$$

As $0<c<1$ and

$$
\begin{aligned}
& D_{\imath}\left[x_{i}, F_{i}\left(x_{1}, \cdots, x_{n}\right)\right] \\
& \quad \leqq \frac{1}{1-c}\left[\left\|x_{\imath}-x_{i}^{m}\right\|+\sum_{k=1}^{n} b_{i k}\left\|x_{k}^{m-1}-x_{k}\right\|+\sum_{k=1}^{n} c_{\imath k}\left\|x_{k}^{m-1}-x_{k}^{m}\right\|\right]
\end{aligned}
$$

it follows that $D_{\imath}\left[x_{i}, F_{i}\left(x_{1}, \cdots, x_{n}\right)\right]=0$. Since $F_{\imath}\left(x_{1}, \cdots, x_{n}\right)$ is a closed set, $x_{i} \in F_{i}\left(x_{1}, \cdots, x_{n}\right)$.

Theorem 3.3 below is a generalization of Matkowski's Theorem 2.1 to multivalued mappings.

Theorem 3.3. Let $X_{i}, i=1, \cdots, n$ be Banach spaces and $a_{i k}$ $i, k=1, \cdots, n$ be positive and $a_{2 k}^{l}$ be defined by (2.5) and (2.6) and fulfill (2.8). Suppose that the transformations $F_{2}: X_{1} \times \cdots \times X_{n} \rightarrow$ CL $\left(X_{i}\right), i=1, \cdots, n$ satisfy

$$
H_{i}\left[F_{i}\left(x_{1}, \cdots, x_{n}\right), F_{i}\left(z_{1}, \cdots, z_{n}\right)\right] \leqq \sum_{k=1}^{n} a_{i k}\left\|x_{k}-z_{k}\right\|
$$


for all $x_{j}, z_{j} \in X_{j}, j=1, \cdots, n$. Then the operator $F=\left(F_{1}, \cdots, F_{n}\right)$ has a fixed point, i.e., there exist points $x_{i} \in X_{i}$, such that $x_{i} \in$ $F_{i}\left(x_{1}, \cdots, x_{n}\right)$ for all $i=1, \cdots, n$. $c=0$.

Proof. In Theorem 3.2, let $c_{i k}=0, b_{i k}=a_{i k}, i, k=1, \cdots, n$ and

The following is the multivalued version of Altman's Theorem 2.2 .

THEOREM 3.4. Suppose a nonlinear closed operator $P: D(P) \subset$ $X \rightarrow \mathrm{CL}(Y)$ has a bounded contractor $\Gamma$ satisfying

(a) $x+\Gamma(x) y \in D(P)$, whenever $x \in D(P), y \in Y$, $D(P)$ being the domain of $P$;

(b) $H[P(x+\Gamma(x) y), P x+y] \leqq q\|y\|$, $x \in D(P), \quad y \in Y, \quad 0<q<1$;

Then there exists $x \in D(P)$ such that $\theta \in P x$, where $\theta$ is the zero element of $Y$.

Proof. For $n=1$, Theorem 3.1 reduces to the above theorem for the choice $c_{i k}=0, b_{i k}=a_{i k}, i, k=1, \cdots, n$ i.e., $b_{11}=a_{11}=q<1$, and $c=0$.

Besides, Theorem 3.1 yields as corollaries several fixed point theorems for single-valued mappings including the following theorem proved elsewhere (Theorem 2.1, [2]).

THEOREM 3.5. Let $X_{i}, Y_{i}, i=1, \cdots, n$ be Banach spaces and $T_{i}: D \subset X_{1} \times \cdots \times X_{n} \rightarrow Y_{i}, i=1, \cdots, n$ be closed non-linear operators. Suppose that there exist bounded linear operators $\Gamma_{i}\left(x_{i}\right): Y_{i} \rightarrow X_{i}$, $i=1, \cdots, n$ such that

$$
\begin{aligned}
& \left(x_{1}+\Gamma_{1}\left(x_{1}\right) y_{1}, \cdots, x_{n}+\Gamma_{n}\left(x_{n}\right) y_{n}\right) \in D \\
& \text { whenever } \quad\left(x_{1}, \cdots, x_{n}\right) \in D, \quad y_{i} \in Y_{i}, \quad i=1, \cdots, n ; \\
& \left\|T_{i}\left(x_{1}+\Gamma_{1}\left(x_{1}\right) y_{1}, \cdots, x_{n}+\Gamma_{n}\left(x_{n}\right) y_{n}\right)-T_{i}\left(x_{1}, \cdots, x_{n}\right)-y_{i}\right\| \\
& \quad \leqq \sum_{k=1}^{n} a_{i k}\left\|y_{k}\right\|,
\end{aligned}
$$

where the nonnegative numbers $a_{i k}, i, k=1, \cdots, n$ are defined by (2.5) and (2.6) and fulfill (2.8); 


$$
\left\|\Gamma_{i}\left(x_{i}\right)\right\| \leqq B, \quad i=1, \cdots, n, \quad\left(x_{i}, \cdots, x_{n}\right) \in D .
$$

Then the system of operator equations

$$
T_{i}\left(x_{1}, \cdots, x_{n}\right)=y_{i}, \quad i=1, \cdots, n
$$

has a solution in $D$ for arbitrary $y_{i} \in Y_{i}, i=1, \cdots, n$.

Proof. In Theorem 3.1, let $c_{i k}=0, b_{i k}=a_{i k}, i, k=1, \cdots, n$ and $c=0$. Define $P_{i}\left(x_{1}, \cdots, x_{n}\right)=\left\{T_{i}\left(x_{1}, \cdots, x_{n}\right)\right\}$ for $\left(x_{1}, \cdots, x_{n}\right) \in D, i=$ $1, \cdots, n$. Clearly the assumptions of Theorem 3.1 are satisfied and hence the system of equations (3.20) has a solution in $D$.

The above Theorem proved in [2] unified, in the setting of Banach spaces, Altman's extension of the contraction principle and Matkowski's fixed point theorem.

\section{REFERENCES}

1. M. Altman, Contractors and contractor directions, Theory and Applications, Marcel Dekker, New York, 1977.

2. . K. Balakrishna Reddy and P. V, Subrahmanyam, Altman's contractors and Matkowski's fixed point theorem, to appear in J. Nonlinear Analysis, Theory methods and applications, 1981.

3. H. Covitz and S. B. Nadler, Jr., Multivalued contraction mappings in generalized metric spaces, Israel J. Math., 8 (1970), 5-11.

4. S. Czerwik, A fixed point theorem for a system of multivalued transformations, Proc. Amer. Math. Soc., 55 (1976), 136-139.

5. J. Matkowski, Some inequalities and generalization of Banach's principle, Bull. Acad. Polon. Sci. Sér. Sci. Math. Astronom. Phys., 21 (1973), 323-324.

6. - Integrable solutions of functional equations, Dissert. Math. (Rozprawy Mat.), CXXVII (1975).

7. S. B. Nadler, Jr., Multivalued contraction mappings, Pacific J. Math., 30 (1969), 475-488.

8. - Some results on multivalued contraction mappings, Lecture Notes in Math., Vol. 171, Springer-Verlag, Berlin 1970, 64-69.

9. S. Reich, Kannan's fixed point theorem, Boll. Un. Mat. Ital., 4 (1971), 1-11.

Received September 3, 1980.

The Ramanujan Institute

UNIVERSITY OF MADRAS

MADRAS 600005

INDIA

AND

INDIAN INSTITUTE OF TECHNOLOGY

MADRAS 600036

INDIA 


\section{PACIFIC JOURNAL OF MATHEMATICS}

\section{EDITORS}

DONALD BABBITT (Managing Editor)

University of California

Los Angeles, California 90024

\section{Hugo Rossi}

University of Utah

Salt Lake City, UT 84112

C. C. MOore and Arthur AGuS

University of California

Berkeley, CA 94720
J. DugundJI

Department of Mathematics University of Southern California Los Angeles, California 90007

R. FinN and J. Milgram Stanford University Stanford, California 94305

ASSOCIATE EDITORS
R. ARENS
E. F. BECKENBACH
B. H. NeumanN
F. WOLF
K. YOSHIDA

\section{SUPPORTING INSTITUTIONS}

UNIVERSITY OF ARIZONA

UNIVERSITY OF BRITISH COLUMBIA

CALIFORNIA INSTITUTE OF TECHNOLOGY

UNIVERSITY OF CALIFORNIA

MONTANA STATE UNIVERSITY

UNIVERSITY OF NEVADA, RENO

NEW MEXICO STATE UNIVERSITY

OREGON STATE UNIVERSITY
UNIVERSITY OF OREGON

UNIVERSITY OF SOUTHERN CALIFORNIA

STANFORD UNIVERSITY

UNIVERSITY OF HAWAII

UNIVERSITY OF TOKYO

UNIVERSITY OF UTAH

WASHINGTON STATE UNIVERSITY

UNIVERSITY OF WASHINGTON 


\section{Pacific Journal of Mathematics}

Vol. 99, No. $1 \quad$ May, 1982

Mariano Giaquinta, Jindrich Necas, O. John and J. Stará, On the

regularity up to the boundary for second order nonlinear elliptic systems . . 1

Siegfried Graf, Realizing automorphisms of quotients of product $\sigma$-fields . . 19

Alfred Washington Hales and Ernst Gabor Straus, Projective colorings . . . 31

Sandra Hayes, The weak Nullstellensatz for finite-dimensional complex

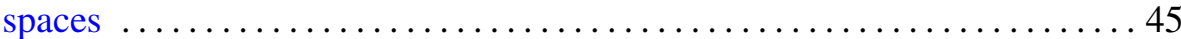

Gerald Norman Hile and Murray Harold Protter, The Cauchy problem

and asymptotic decay for solutions of differential inequalities in Hilbert

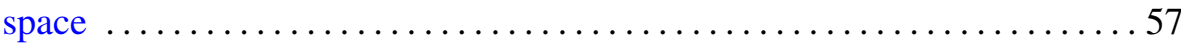

Robert D. Little, Projective space as a branched covering with orientable

branch set ......................................... 89

Jaroslav Mach, On the proximinality of Stone-Weierstrass subspaces . . . . . 997

John C. Morgan, II, On product bases ...................... 105

K. Balakrishna Reddy and P. V. Subrahmanyam, Altman's contractors

and fixed points of multivalued mappings . .................. 127

James Ted Rogers Jr., Decompositions of homogeneous continua . . . . . . . 137

Ahmed Ramzy Sourour, Characterization and order properties of

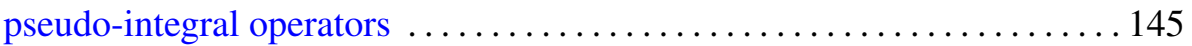

Robert Moffatt Stephenson Jr., Pseudocompact and Stone-Weierstrass

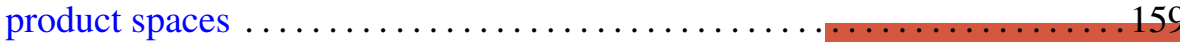

Bruce Stewart Trace, On attaching 3-handles to a 1-connected

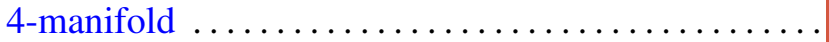

Akihito Uchiyama, The construction of certain BMO functions and the corona problem

Thomas Alva Whitehurst, An application of orthogonal polynomials to random walks ..............................

David J. Winter, Root locologies and idempotents of Lie and nonassociative algebras

William Robin Zame, The classification of uniform algebras on plane domains 